\title{
The Price Forecast Model of China-made Large Aircraft Based on Partial Least Squares Regression
}

\author{
Pei Fang ${ }^{1, a}$, Lu Wang ${ }^{2, b}$ and Shuhua Mao ${ }^{3, c}$ \\ ${ }^{1}$ Wuhan University of Technology, College of Computer Science \& Technology, Peace Avenue \\ 1040, Wuhan, Hubei Province, China \\ ${ }^{2}$ Wuhan University of Technology, School of Economics, Luoshi Road 122, Xiongchu Avenue, \\ Wuhan, Hubei Province, China \\ ${ }^{3}$ Wuhan University of Technology, School of Science, Peace Avenue 1040, Wuhan, Hubei Province, \\ China \\ a470810840@qq.com, b295276730@qq.com, '651332723@qq.com
}

Keywords: domestic large aircraft; price forecast; partial least squares regression; discount factor; mathematical model

\begin{abstract}
This article adopts partial least squares regression method to forecast the price of domestic (China-made) large aircraft C919. W ith analysis of the pricing background and the relationship between performance index and price of foreign aircaft, we build preliminary model. And comparing with other modeling methods by calculating average relative error, we find the preliminary model fits better. Considering the difference in environment between domestic and foreign market, we propose the concept of discount factor. And the factor is equal to 0.6529 by analyzing domestic and foreign small aircrafts of the sam e type. Finally through modified model we get the forecast price, namely 48.95 million dollars per aircraft. Th e forecasting model and discount factor have some reference value to the price forecast of domestic large aircraft.
\end{abstract}

\section{Introduction}

C919 is Chinese self-developed large aircraft. The project of it started in November, 2008. Its first flight is expected in 2014. And it's planned to obtain airworthiness certificate and put into service in 2016. When developing a new aircraft, we should consider lots of econom ic problems besides technique details. Among them, the questions whether and how long the airc raft manufacturer can recover the original investment outstand. To answer these questions, price forecast of the new aircraft is necessary.

Partial least squares regression (hereinafter referred to as PLSR) can screen independent variables briefly. Its rich aided analysis technique can achieve screening while modeling and overcom e bad influence caused by variables' multiple correlation ${ }^{[1]}$.

In literature [2,3] by Li Shouan etc(2005,2006), the comparison among PLSR, regression without screening variables and stepwise multiple regression shows that PLSR is $\mathrm{m}$ ore accurate in price forecast of military aircraft than the other two models. Compared with price forecast relied on manufacturing cost and period expenses, the similar aircraft price forecast model based on analysis of military aircraft in literature [4] by Li Shouan et c (2007) is better. The price forecast background of the domestic large aircraft C919 is very similar to military aircraft. They both have a small number of sample data and a large number of price driving factors, as well as having few types. Besides, neither of their data collection is sound and their cost of development and manufacturing isn't available to the public.

In literature [5] by LI Zhanke etc (2011), PLSR is adopted to forecast the price of C919, but the value of equalization-engineering-value-ratio is much too subjective and brief. In this article, we also apply PLSR to forecast the price of C919. And combining with China's actual situation, we deal with domestic small aircraft with PLS R, calculate discount factor, get modi fied model and obtain reasonable forecast price in ensured market competitiveness. Through the above work, we expect to provide some guidance for the price forecast of domestic large aircraft. 


\section{Introduction of Regression Model}

General linear relationship and log-linear relatio nship are selected to analyze here. To choose better model, we compare the fitting precision of the two methods.

General linear regression form is as follows

$y=\alpha_{0}+\alpha_{1} x_{1}+\alpha_{2} x_{2}+\ldots \ldots+\alpha_{n} x_{n}$

Log-linear regression form is as follows

$\ln y=\beta_{0}+\beta_{1} \ln x_{1}+\beta_{2} x_{2}+\ldots \ldots+\beta_{n} x_{n}$

Considering modeling problem with single dependent variable $y$ and $p$ independent variables $x_{1}, x_{2}, \ldots \ldots, x_{p}$, the basic practice of PLSR is shown below. Primarily, extract the first component $t_{1}$ $\left(t_{1}\right.$ is the linear combination of $x_{1}, x_{2}, \ldots \ldots, x_{p}$, and contains as much original information as possible. It's required that the relevance between $t_{1}$ and $y$ reaches the $\mathrm{m}$ aximum. Then establish the regression equation of dependent variables $y$ and $t_{1}$. If its precision is satisfying, then the practice ends. Otherwise the extraction of the second component is needed, and it continues until reaching the required precision. Given that $m$ components $t_{1}, t_{2}, \ldots \ldots, t_{m}$ are extracted ultimately, PLSR will establish the regression equation of $y$ and $t_{1}, t_{2}, \ldots \ldots, t_{m}$, and then tran sform it into th e regression equation of $y$ and original independent variables, namely PLSR equation.

\section{The Preliminary Model of PLSR}

C919 is large aircraft, so regardless of performance or pricing, it's more reasonable to refer to other large commercial aircrafts' data than small aircrafts' and helicopters. A variety of factors considered, we choose the performance index and prices of 26 commercial aircrafts from the Boeing Company and Airbus as the basic data of PLSR modeling. Theaircrafts' types and specific data are shown in the following table $1^{[6]}$.

Table 126 Large Commercial Aircrafts' Types and Specific Data

\begin{tabular}{cccccccccc}
\hline Aircraft Type & $\begin{array}{c}\text { Capacity } \\
\text { [Number } \\
\text { of people] }\end{array}$ & $\begin{array}{c}\text { Span } \\
{[\mathbf{m}]}\end{array}$ & $\begin{array}{c}\text { length } \\
{[\mathbf{m}]}\end{array}$ & $\begin{array}{c}\text { Height } \\
{[\mathbf{m}]}\end{array}$ & $\begin{array}{c}\text { Maximum } \\
\text { fuel load } \\
{[\mathbf{k g}]}\end{array}$ & $\begin{array}{c}\text { Maximum } \\
\text { takeoff weight } \\
{[\mathbf{k g}]}\end{array}$ & $\begin{array}{c}\text { Maximum } \\
\text { range } \\
{[\mathbf{k m}]}\end{array}$ & $\begin{array}{c}\text { Maximum engine } \\
\text { thrust } \\
{[\mathbf{k N ]}}\end{array}$ & $\begin{array}{c}\text { Average price } \\
{[\mathbf{m i l l i o n}]}\end{array}$ \\
\hline $737-600$ & 110 & 34.3 & 31.2 & 12.6 & 22000 & 65090 & 6000 & 91.6 & 55 \\
$737-700$ & 126 & 34.31 & 33.6 & 12.55 & 22000 & 60330 & 6230 & 116 & 64 \\
$737-800$ & 162 & 34.31 & 39.5 & 12.55 & 22000 & 70553 & 5665 & 124 & 76.75 \\
$\vdots$ & $\vdots$ & $\vdots$ & $\vdots$ & $\vdots$ & $\vdots$ & $\vdots$ & $\vdots$ & $\vdots$ & $\vdots$ \\
$350-900$ & 300 & 61.1 & 58.8 & 17.2 & 97370 & 265000 & 13900 & 774 & 240.6 \\
380 & 674 & 79.8 & 73 & 24.1 & 217000 & 560000 & 15100 & 1208 & 327.4 \\
C919 & 162 & 36.1 & 38.6 & 12.6 & 16800 & 72500 & 5555 & 124 & $?$ \\
\hline
\end{tabular}

In table I we om it the data of following 21 aircrafts: 737-900ER, 747-400/-400ER, 747-8, 767-200ER, 767-300ER, 767-400ER, 777-200ER, 777- 200LR, 777-300ER, 787-3, 787-8, 787-9, $318,319,320,321,330-200,330-300,340-300,340-\quad 500,340-600$. More inform ation can be referred to the website we give in [6]. The correlation coefficient matrix is given below:

$\left(\begin{array}{lllllllll}1 & 0.9012 & 0.8948 & 0.8955 & 0.9116 & 0.9244 & 0.7230 & 0.6599 & 0.9224 \\ 0.9012 & 1 & 0.9448 & 0.9420 & 0.9492 & 0.9567 & 0.8693 & 0.7494 & 0.9799 \\ 0.8948 & 0.9448 & 1 & 0.8652 & 0.9045 & 0.9194 & 0.8427 & 0.6696 & 0.9589 \\ 0.8955 & 0.9420 & 0.8652 & 1 & 0.9220 & 0.9141 & 0.7771 & 0.6330 & 0.9134 \\ 0.9116 & 0.9492 & 0.9045 & 0.9220 & 1 & 0.9811 & 0.8447 & 0.7253 & 0.9486 \\ 0.9244 & 0.9567 & 0.9194 & 0.9141 & 0.9811 & 1 & 0.8702 & 0.7193 & 0.9711 \\ 0.7230 & 0.8693 & 0.8427 & 0.7771 & 0.8447 & 0.8702 & 1 & 0.6088 & 0.8954 \\ 0.6599 & 0.7494 & 0.6696 & 0.6330 & 0.7253 & 0.7193 & 0.6088 & 1 & 0.7150 \\ 0.9224 & 0.9799 & 0.9589 & 0.9134 & 0.9486 & 0.9711 & 0.8954 & 0.7150 & 1\end{array}\right)$


From the matrix above, we can see that the correla tion is large. In this situation, y denotes the average price of aircraft, $x_{1} \sim x_{8}$ respectively denote capacity, span, length, height, maximum fuel load, maximum takeoff weight, maximum range, maximum engine thrust and average price.

Under the control of cro ss validation, we extract th e principal components of all independent variables to do regression analysis. Then we get the following preliminary general linear PLSR model of forecast price of C919,

$$
\begin{aligned}
y= & -77.1711+0.0972 x_{1}+1.2517 x_{2}+1.4658 x_{3}+0.1885 x_{4}+0.1786 \times 10^{-4} x_{5}+0.8580 \times 10^{-4} x_{6} \\
& +0.4471 \times 10^{-2} x_{7}+0.7181 \times 10^{-2} x_{8}
\end{aligned}
$$

The effect of every independent variable $\quad x_{j}$ on dependent variable $y$ can be measured by variable importance of projection index VIP. VIP is defined ${ }^{[7]}$ as follows,

$$
\begin{aligned}
& V I P=\sqrt{\frac{p}{R d\left(y ; t_{1}, t_{1}, \cdots t_{m}\right)} \sum_{h=1}^{m} R d\left(y ; t_{h}\right) \omega_{h j}^{2}} \\
& \text { in which, }\left\{\begin{array}{l}
R d\left(y ; t_{1}, t_{1}, \cdots t_{m}\right)=\sum_{h=1}^{m} R d\left(y ; t_{h}\right) \\
R d\left(y ; t_{h}\right)=r^{2}\left(y, t_{h}\right)
\end{array}\right.
\end{aligned}
$$

In the formula above, $\omega_{h j}$ is the first $j$ th component of $\omega_{j} \cdot r\left(y, t_{h}\right)$ is the correlation coefficient of $y$ and $t_{h}$.

Figure 1 below is the histogram of VIP. From the figure we can see that the VIP values of all independent variables are in the nearby of value 1 . This indicates that the explanatory ability of all independent variables on dependent variable is equivalent.

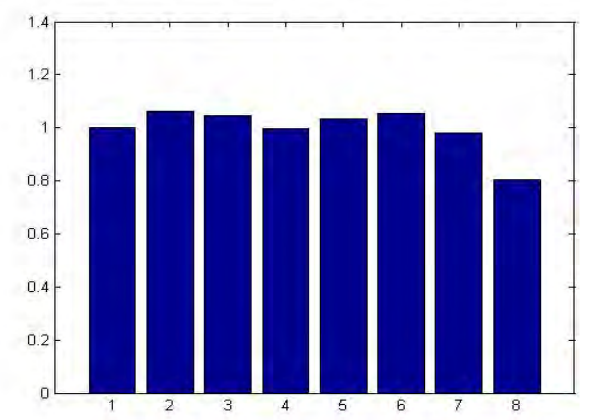

Fig. 1 Histogram of VIP

Then we calculate precision and fi nd that the average relative e rror of this regression $\mathrm{m}$ odel is $3.84 \%$, which indicates that the model fits well and is feasible. However, the average relative error of log-linear regression model is $4.47 \%$, thus showing that general linear regression is better. Figure 2 below are fitting precision maps of all samples.
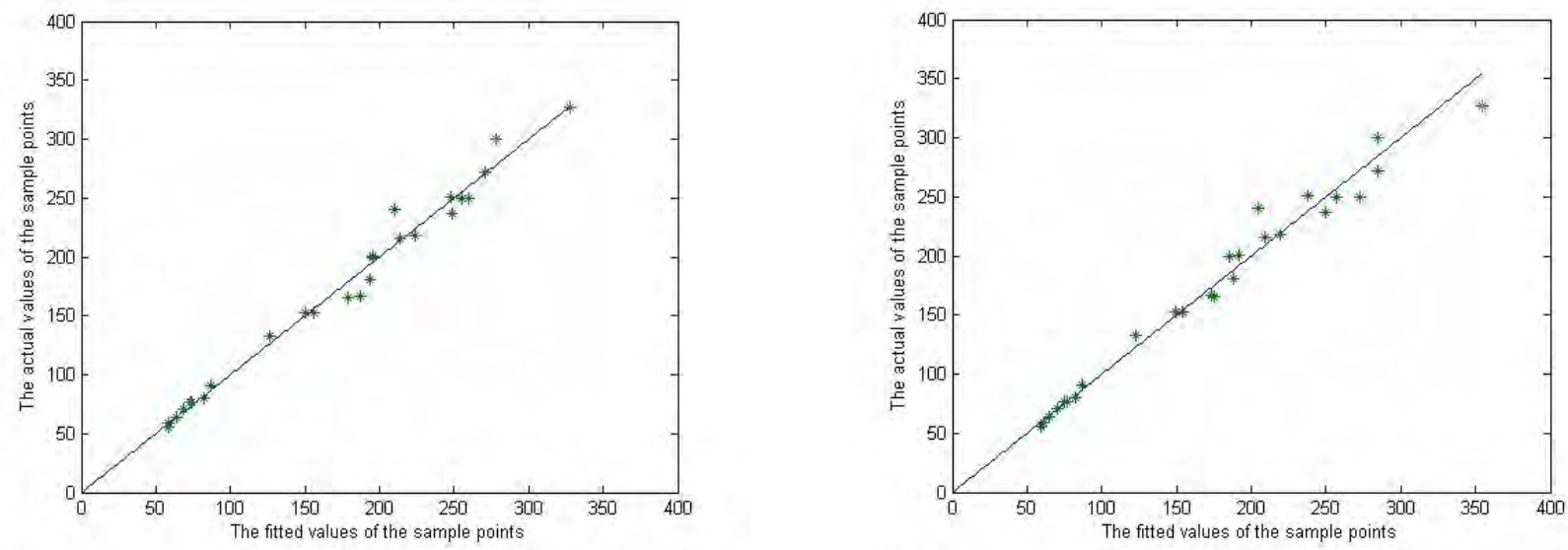

Fig. 2 Fitting precision map based on general linear regression \& Fitting precision map based on log-linear regression. 
Moreover, by calculation we know that the averagerelative error of least squares regression model is $3.96 \%$, which is less precise than that of PLSR. So this article chooses the relatively most precise PLSR as the preliminary model. Feed the performance data of C919 (see Table 1) into linear PLSR equation (3) and we get preliminary value of forecast price, namely 74.97 million dollars per aircraft.

\section{PLSR Model Modified by Discount Factor}

The price of aircraft is influenced by lots of ex ternal factors, including inflation rate and th e competition among aircraft suppliers. And the case ex ists that suppliers offer discounts to airlines while raising catalog price. The increase rate of price is not fixed and there is much uncertainty. For these reasons, the effect of time is not considered in this article.

In this article the original data to forecast the price of C919 are adopt from foreign large aircrafts' performance data and prices accordingly. During the process of forecasting, we neglect the difference between domestic and foreign market. The distinction in labor cost, manufacturing efficiency, policy and laws, marketing methods and many other factor s have non-negligible impact on the pricing of aircraft. So modification of the preliminary model is needed.

As we know, China's self-developed aircraft ARJ-21 has put into production and service. ARJ-21 is a kind of small commercial aircraft used for extension operation. Once we figure out the ratio of the price of domestic aircraft to the price of foreign aircraft of the same type, then we can m odify the model and obtain a more reasonable one to forecast the price of domestic aircraft.

The performance data and prices of foreign aircra fts are available. We can use these data and the original model in the previous part to forecast the price of ARJ-21 $P$. And the real price of ARJ-21 $P^{\prime}$ is known, then the ratio we need is $\frac{P^{\prime}}{P}$. We use $\mathrm{C}$ to denote $\frac{P^{\prime}}{P}$, and give it the $\mathrm{m}$ eaning of discount factor. With the price got from original model multiplied by $\mathrm{C}$, we gain relatively precise forecasting price.

When using PLSR to forecas t the price of ARJ-21, we choose the same standard as the origin al model so as to get a $\mathrm{m}$ ore reasonable discount factor. Through searching, we find the data of three foreign small aircraft shown in the table 2 below ${ }^{[6]}$.

Table 2 The Performance Data and Prices of Samll Aircrafts

\begin{tabular}{|c|c|c|c|c|c|c|c|c|c|}
\hline Aircraft Type & $\begin{array}{l}\text { Capacity } \\
\text { [Number } \\
\text { of people] }\end{array}$ & $\begin{array}{c}\text { Span } \\
{[\mathrm{m}]}\end{array}$ & $\begin{array}{c}\text { length } \\
\text { [m] }\end{array}$ & $\begin{array}{c}\text { Height } \\
\text { [m] }\end{array}$ & $\begin{array}{c}\text { Maximum fuel } \\
\text { load } \\
{[\mathrm{kg}]}\end{array}$ & $\begin{array}{c}\text { Maximum } \\
\text { takeoff weight } \\
{[\mathrm{kg}]} \\
\end{array}$ & $\begin{array}{c}\text { Maximum } \\
\text { range } \\
\text { [km] }\end{array}$ & $\begin{array}{c}\text { Maximum engine } \\
\text { thrust } \\
{[\mathrm{kN}]}\end{array}$ & $\begin{array}{c}\text { Average } \\
\text { price } \\
\text { [million] }\end{array}$ \\
\hline CRJ-700 & 70 & 23.2 & 32.51 & 7.57 & 9306.91 & 33000 & 3124 & 61.3 & 36 \\
\hline CRJ-900 & 90 & 23.2 & 36.19 & 7.57 & 9306.91 & 36500 & 2778 & 64.5 & 41.6 \\
\hline CRJ-200 & 50 & 21.21 & 26.77 & 6.22 & 4653.5 & 21500 & 1825 & 40.98 & 22 \\
\hline ARJ-21 & 90 & 27.288 & 33.464 & 8.442 & 10386 & 40500 & 2225 & 68.14 & 30 \\
\hline
\end{tabular}

Then we get the following price forecast model of small aircraft

$y^{\prime}=-29.5357+0.1331 x_{1}+0.7322 x_{2}+0.4791 x_{3}+1.0793 x_{4}+0.0313 \times 10^{-2} x_{5}+0.0214 \times 10^{-2} x_{6}$

$$
-0.0027 \times 10^{-1} x_{7}+0.1035 x_{8}
$$

Feed the data of ARJ-21 (see Tab le 2) into equation (6), and get the forecasting price $P$, namely 45.95 million dollars per aircraft. While the real price of ARJ-21 is $P^{\prime}$, namely 30 million dollars per aircraft. Then the discount factor is $\frac{P^{\prime}}{P}$, namely 0.6529 . The final price forecast model is

$$
M=C \times y
$$

In which $\mathrm{M}$ is the final forecast price of $\mathrm{C} 919, y$ is the preliminary forecast price, $\mathrm{C}$ is discount factor. Then the final forecast price is

$M=0.6529 \times 74.97=48.95$

Namely 48.95 million dollars per aircraft.

\section{Conclusion}


This article aims to forecast the price of domestic large commercial aircraft. To reach the goal, we find the relationship between performance index and price of foreign aircraft by regression methods. Though comparison we figure out that under the for ecast background, general linear PLSR is more precise than log-linear regression and least squares regression.

Combining with the real pricing situation of domestic aircraft, we modify the o riginal model through discount factor which considers actual effect s. Compared with literature [5], this article provides a more reasonable method for the quantification of equalization-engineering-value-ratio.

The final forecast price of C919 gai ned in this article is 48.95 million dollars per aircraft. And China's Ministry of Commerce once disclosed to the Xinhua News Agency that the market price of C919 would be less th an $50 \mathrm{~m}$ illion dollars per aircraft ${ }^{[8]}$. This also proves that our result is reasonable and feasible.

Although this model barely takes the influence of tme into consideration, it offers some help to the price forecast and pricing of domestic large aircraft.

\section{References}

[1] Feng Zunde, Lu Xiushan, Shi Yufeng et al. Application of partial least squares regression in data analysis of mining subsidence[J]. Transactions of Nonferrous Metals Society of China, 2005, 15(S1): 148-150.

[2] Li Shouan, Zhang Hengxi, Li Dongxia et al. Battleplan acquisition cost forecast based on partial least2squares regression[J]. Journal of Naval University of Engineering, 2005, 17(4): 64-68.

[3] Li Shouan, Zhang Hengxi, Tong Zhongxiang et al . Application of Pa rtial Least2squares Regression to the Acqui sition Cost Estim ating of Military Aircrafts[J]. Acta Aeronoutica et Astronautica Sinica, 2006, 27(3): 600-604.

[4] Li Shouan, Zhang Hengxi, Song Bi feng et al. Research into Warplane Procurement Price Prediction[J]. Fire Control and Command Control, 2007, 32(1): 81-83.

[5] LI Zhanke, FU Jinfeng. Research o $\mathrm{n}$ the cost forecast of civil transpo rts based on partial leas $\mathrm{t}$ squares regression[J].Flight Dynamics,2011,29(6):81-83.

[6] China Holiday. 377 types of aircraft $m$ odels [EB/OL]. http://www.china-holiday.com /air /flight/AircraftType/aircraftmodel.htm, 2012.

[7] Wang Huiwen, Wu Zaibing, Meng Jie. Partial Least-Squares Regerssion Linear and NonLinear Methods[M]. Beijing: National Defence Industry Press,2006:119-120.

[8] Xinhua. China-made large aircraft C919 cha llenge Boeing and Ai rbus with the price advantage[EB/OL]. http://news.xinhuanet.com/fortune/2010-11/17/c_12782905.htm, 2012. 